DOI: http://doi.org/10.4038/sljma.v22i1.5354

\title{
Exposure of health staff to COVID-19 infection: causes and recommendations for reduction of exposure
}

\author{
Wickramasinghe SC, Perera VUE, Wickramasinghe A, Rajasinghe SV, \\ Prabha Kumari AMU, Fernando N.
}

\begin{abstract}
Introduction: The coronavirus (SARS-CoV-2) spreads predominantly between people who are in close contact with an infected person. Hence, the frontline health staff members are more vulnerable for exposure due to rising number of cases.
\end{abstract}

Objectives: To describe the possible causes for exposure of health staff in Sri Lanka for COVID-19 infection and to review suggestions made by health staff for minimizing such exposure.

Methods: A descriptive cross-sectional study was conducted from October 2020 to December 2020. A self administered questionnaire was given to health staff when they were admitted to a quarantine center and collected on discharge or transfer. Data was analyzed using descriptive statistics.

Results and discussion: There were 80 participants with a response rate of $100 \%$. Majority $(n=79,98.8 \%)$ were exposed to a confirmed/suspected case within their health institution and most ( $60 \% ; n=48)$ were exposed within the ward they work.

Source of exposure was mostly a patient $(55 \% ; n=44)$ or a staff member $(33.7 \% ; n=27)$. At the time of exposure, majority wore only a facemask $(n=43,53.8 \%)$.

Shortage of Personal Protective Equipment (PPE), inadequate training on infection control, Incorrect contact history provided by patients were stated as the main causes $(75 \%)$ of exposure. $38 \%$ of health staff members share meals with their colleagues at workplace. Conclusions and Recommendations: All staff categories should be provided with necessary PPE. Regular training programs on infection control need to be conducted covering all staff categories. A suitable arrangement to take meals individually must be developed.

Keywords: Health staff, COVID-19 exposure

\section{Introduction}

The SARS-CoV-2 virus spreads primarily between people who are in close contact (6 feet) with an infected person through respiratory pathways, although it can also be transmitted through contact with contaminated surfaces or objects[1]. Currently, the COVID-19 infection is being declared as a pandemic by the World Health Organization [2].
COVID-19 has exposed health workers to exceptional level of risk as they are at front line of the COVID-19 prevention, control, and management. In fact, data from many countries across WHO regions show that COVID-19 infection rate among health workers is much higher than those in the general population [2]. Among the factors leading to increased infection rate, shortage of Personal Protective Equipment, high workload, lack of knowledge and training related to prevention of COVID-19 infection are of importance [4].

The current outbreak of COVID-19, places healthcare workers at greater risk of infection as they are in close contact with patients. Ministry of Health has obtained the service of two hotels to place staff under quarantine. This has provided an opportunity to study the possible causes of exposure of health workers for COVID-19 infection.

General Objective: To describe the possible causes of exposure of health staff in Sri Lanka for COVID-19 infection and to review suggestions made by health staff for minimizing such exposure.

\section{Specific Objectives:}

1. To describe the socio demographic characteristics of the sample;

2. To describe the source of possible infection;

3. To assess the awareness and practice on use of personal protective equipment;

4. To describe the recommendations for staff under quarantine to prevent future staff exposure.

\section{Methodology}

\section{Study Design}

A descriptive cross-sectional study was conducted among health staff who were staying at quarantine centers.

\section{Study period}

October 2020 to December 2020.

\section{Selection Criteria}

All health staff with a history of exposure to a suspected or confirmed case of COVID-19 quarantine during October 2020 and December 2020 in centers organized by the ministry of health was included. 


\section{Sample size}

All staff quarantined from October 2020 to December 2020 was included in the study.

\section{Study Instrument}

Data were obtained through a self-administered questionnaire which collected data on socio demographic characteristics, history of exposure to a patient with COVID-19 and facilities available for personal protection at workplace. The questionnaire was pretested among staff working in curative and preventive sector of Colombo district. The health staff of Sri Lanka army who managed the two centers were trained on the questionnaire and acted as coordinators of the data collection process.

\section{Data collection}

The questionnaire was distributed to the health staff when they were already staying in a quarantine center. They were requested to fill the questionnaire and hand them over on discharge or transfer from the center. It was advised to contact the army health officers if they have any problems in understanding a question when they make daily rounds to measure the temperature.

\section{Results}

\section{Basic information}

A total of 80 participants representing 11 health institutions were included in the analysis with the response rate of $100 \%$. Majority were females $(n=46$, $57.5 \%$ ) and the mean age of the study sample was 37.7 years $(\mathrm{SD}=8.7)$. Most $(\mathrm{n}=34,42.5 \%)$ were nursing officers followed by health assistants $(\mathrm{n}=25,31.3 \%)$ and medical officers $(n=9,11.3 \%)$.

Details related to the exposure of confirmed/suspected case of COVID-19

Majority ( $\mathrm{n}=79,98.8 \%)$ were exposed to confirmed/ suspected cases of COVID-19 within their health institution and $60 \%(n=48)$ were exposed within the hospital ward they work, followed by hospital kitchen $(\mathrm{n}=8,10 \%), \mathrm{ICU}(\mathrm{n}=6,7.5 \%)$ and Operating Theatre $(n=6,7.5 \%)$.

\section{Availability of PPE and distancing}

Source of exposure was a client/patient among 55\% $(n=44)$, or a staff member among $33.7 \%(n=27)$. At the time of exposure, majority wore only a facemask ( $\mathrm{n}=43$, $53.8 \%)$ and about $45 \%(n=36)$ wore both facemasks and gloves. However, only 5 (6.3\%) wore facemasks, gloves and overall at the time of exposure.

With regard to the type of facemask, a great majority $(\mathrm{n}=73,91.3 \%)$ wore a surgical mask, while $6.3 \%(\mathrm{n}=5)$ and $2.4 \%(\mathrm{n}=2)$ wore a $\mathrm{N}-95$ mask and a cloth mask respectively.

Unavailability of overalls $(n=33,41.3 \%)$, gloves $(n=8$, $10 \%)$, sanitizer $(n=5,6.3 \%)$, and soap $(n=3,3.8 \%)$ was reported by the sample.

Among the sample, only $75 \%(n=60)$ were able to maintain one meter gap between each other while working. The reasons for inability to maintain one-meter gap were nature of the job $(n=71,32.9 \%)$, inadequate space $(n=25,32.9 \%)$ and poor attention of staff members $(n=6,7.9 \%)$.

Of the total sample, $76.2 \%(\mathrm{n}=61)$ have a common place to have their meals. Moreover, a considerable proportion $(n=30,37.5 \%)$ have the practice of sharing meals with their colleagues.

\section{Awareness of COVID-19 preventive measures}

Sources of awareness related to prevention of COVID-19 were circulars $(n=30,37.5 \%)$, electronic media $(n=29$, $36.3 \%)$, workplace training $(\mathrm{n}=25,31.3 \%)$, printed media $(\mathrm{n}=17,31.3 \%)$ and online training $(\mathrm{n}=5,6.3 \%)$. Table 1 shows the mode of recieving information related to prevention of COVID-19 according to the staff category.

Table 1: Mode of receiving Information on COVID prevention according to the staff category

\begin{tabular}{lrrrrrrr}
\hline Staff category & \multicolumn{7}{c}{ Mode of awareness } \\
\hline & $\begin{array}{r}\text { Workplace } \\
\text { training }\end{array}$ & $\begin{array}{r}\text { Online } \\
\text { training }\end{array}$ & Circulars & $\begin{array}{r}\text { Electronic } \\
\text { media }\end{array}$ & $\begin{array}{r}\text { Printed } \\
\text { media }\end{array}$ & $\begin{array}{r}\text { Social } \\
\text { media }\end{array}$ & $\begin{array}{r}\text { No } \\
\text { training }\end{array}$ \\
Medical & 1 & 2 & 6 & 4 & 1 & 4 & 2 \\
officers & $(11.1 \%)$ & $(22.2 \%)$ & $(66.7 \%)$ & $(44.4 \%)$ & $(11.1 \%)$ & $(44.4 \%)$ & $(22.2 \%)$ \\
Nursing & 13 & 3 & 18 & 17 & 11 & 14 & 4 \\
officers & $(38.2 \%)$ & $(8.8 \%)$ & $(52.9 \%)$ & $(50 \%)$ & $(32.4 \%)$ & $(41.2 \%)$ & $(11.8 \%)$ \\
PHII & 0 & 0 & 1 & 0 & 0 & 0 & 4 \\
& $(0 \%)$ & $(0 \%)$ & $(20 \%)$ & $(0 \%)$ & $(0 \%) 0$ & $(0 \%) 0$ & $(80 \%)$ \\
Minor Staff & 11 & 0 & 5 & 8 & 5 & 7 & 10 \\
& $(23.9)$ & $(0 \%)$ & $(10.8 \%)$ & $(17.4 \%)$ & $(10.8 \%)$ & $(15.2 \%)$ & $(21.9 \%)$ \\
\hline
\end{tabular}


Forty nine percent $(n=39)$ were satisfied about the training/information they received while $11.3 \%(n=9)$ were not satisfied. However, $40 \%(n=32)$ did not respond to that question.

Majority $(n=51,63.8 \%)$ of the participants requested training on prevention of COVID-19 for health staff but $26.2 \%$ $(n=21)$ did not give any answer. Table 2 shows the results.

Table 2: The need for training according to the staff category

\begin{tabular}{lrrrr}
\hline \multicolumn{1}{l}{ Staff category } & \multicolumn{3}{c}{ Need for future training } \\
\hline & Yes & No & No answer & Total \\
Medical Officers & $6(66.7 \%)$ & $0(0 \%)$ & $3(33.3 \%$ & $9(100 \%)$ \\
Nursing officers & $22(64.7 \%)$ & $6(17.6 \%)$ & $6(17.6 \%)$ & $34(100 \%)$ \\
PHII /Food Inspectors & $3(60 \%)$ & $0(0 \%)$ & $2(40 \%)$ & $5(100 \%)$ \\
Minor Staff Categories & $20(62.5 \%)$ & $2(6.2 \%)$ & $10(31.3 \%)$ & $32(100 \%)$ \\
Total & $51(63.8 \%)$ & $8(10.0 \%)$ & $21(26.2 \%)$ & $80(100 \%)$ \\
\hline
\end{tabular}

Among the reasons of exposing health staff for COVID-19, wrong information given by patients $(\mathrm{n}=60,75 \%)$, more workshifts $(n=53,66.3 \%)$, ignorance of health staff $(n=40,50 \%)$, lack of PPE $(n=32,40 \%)$ and poor knowledge on safety methods $(n=29,36.3 \%)$ were stated by participants.

With regard to measures to be taken to prevent the exposure of health staff, suggestions made by participants are shown in Table 3.

Table 3: Measures to be taken to prevent the exposure of health staff

\begin{tabular}{|c|c|}
\hline Suggested measures & Details \\
\hline $\begin{array}{l}\text { - Provision of adequate facilities } \\
\text { for health staff/other staff }\end{array}$ & $\begin{array}{l}\text { - Provide PPE, transport and accommodation } \\
\text { - Pay special attention on nutritional status of health workers } \\
\text { - Proper sanitization of common places such as toilets, rest rooms, } \\
\text { meal rooms etc. } \\
\text { - Provide PPE for all cleaning service staff members }\end{array}$ \\
\hline
\end{tabular}

- Necessary administrative decisions by higher authorities
- Reduce excessive number of duty shifts per person

- Minimize duty shifts for pregnant and other workers who have chronic diseases

- Ensure adequate rest between two duty shifts

- Reduce the duration of a single work shift

- Divide whole staff into groups and allocate duty on shift basis

- Restrict hospitalization of patients as far as possible

- Limit visitors to the hospitals

- Proper triage of patients according to the risk for COVID-19

- Minimize the number of ward rounds per day

- Need to have separate COVID ward for each specialty

- Perform random PCR among staff members

- Perform PCR on suspected patients
- Training/education for health staff
- Conduct special training program for health workers on COVID-19 and Its prevention

- Make the staff aware about aerosol generation procedures and preventive measures

- Display a poster on how to wear and remove full PPEs 


\section{Discussion}

The aim of this study was to explore the causes for exposure of health staff for COVID-19 infection and to review the suggestions made for health staff for minimizing the exposure of COVID-19 infection among health staff. Nursing officers were the predominant healthcare workers among the frontline health workers exposed to COVID-19 infection as found in other studies [6]. Further, this study demonstrated that most of the exposure of health staff members to COVID-19 takes place within the hospital premises mainly in the wards through patients. Similar findings were observed in a rapid review conducted among health workers to assess COVID-19 risk factors [7]. In this study, shortage of PPE and other healthcare facilities were seen in some institutions and this issue was highlighted in many other studies [8-10] elsewhere.

As Wang, Zhou and Liu [6] pointed out, inadequate training on infection prevention and control for frontline healthcare workers is also evident in the present study. This may be due to the reason that they have not had sufficient time for regular training and practice. Even though the lack of professional supervision in infection control is also highlighted in other studies $[6,11]$, it was not revealed in the present study.

The main reason for exposing health staff for COVID-19 in present study was the wrong information given by patients related to contact history of COVID-19. Similar finding was noted by Das [12] as stigma discourage people to report the disease and take therapeutic action, hence deferring revealing, management and control of the disease.

This study revealed that even during the pandemic period, considerable proportion of health staff members used to share the meals with their colleagues at workplace. Further, in some places, maintaining an adequate distance between two people was not possible due to lack of space and the nature of their job. Therefore, such practices and factors lead to spread of infection among staff members [13].

\section{Conclusions and recommendations}

1. Exposure of majority of the staff members to COVID-19 takes place within the hospital premises mainly in the wards through patients. Therefore, special precautions should be taken to prevent spread within the hospital/workplace.

2. Inadequacy of PPE and other healthcare facilities was reported. Thus, it is recommended to provide adequate PPE for personal protection for all staff categories.
3. With regard to receiving information/training related to prevention of COVID-19, there was substantial disparity among all staff categories even within the same institution. Hence, systematic training needs to be conducted for all staff categories in a uniform manner.

4. Majority of staff had a common place to have meals in their workplaces and some had the practice of sharing their meals with others. Therefore, measures should be taken to educate health staff and to prevent such practices in order to minimize spread of COVID-19 among health staff members.

\section{References}

1. Wang C, Horby PW, Hayden FG, Gao GF. A novel coronavirus outbreak of global health concern. The lancet. 2020 Feb 15;395(10223):470-3.

2. World Health Organization 2020. News item. Keep health workers safe to keep patients safe: WHO. 17 September, 2020.

3. Daily updated report of COVID-19 in Sri Lanka. Epidemiology Unit. 16 March 2020.

4. Annual health bulletin 2014. Medical Statistics Unit, Ministry of Health, Nutrition and Indigenous Medicine, Sri Lanka. 2016.

5. Asemahagn MA. Factors determining the knowledge and prevention practice of healthcare workers towards COVID-19 in Amhara region, Ethiopia: a cross-sectional survey. Tropical medicine and health. 2020 Dec;48(1):1-1.

6. Wang J, Zhou M, Liu F. Reasons for healthcare workers becoming infected with novel coronavirus disease 2019 (COVID-19) in China. J Hosp infect. 2020 Mar 6;105(1).

7. Mhango M, Dzobo M, Chitungo I, Dzinamarira T. COVID-19 risk factors among health workers: a rapid review. Safety and health at work. 2020 Jun 6.

8. Schwartz J, King CC, Yen MY. Protecting healthcare workers during the coronavirus disease 2019 (COVID-19) outbreak: lessons from Taiwan's severe acute respiratory syndrome response. Clinical Infectious Diseases. 2020 Jul 28;71(15):858-60.

9. Grimm CA. Hospital experiences responding to the COVID-19 pandemic: results of a national pulse survey March 23e27, 2020; 2020. https:// 
justthenews.com/sites/default/files/2020-04/ HHS2020ReportPandemicHospitals.pdf.

10. Bai $Y$, Wang $X$, Huang Q, Wang H, Gurarie D, Ndeffo-Mbah M, Fan F, Fu P, Horn MA, Xu S, Mondal A. SARS-CoV-2 infection in health care workers: a retrospective analysis and a model study. medRxiv. 2020 Jan 1.

11. Xiong Y, Peng L. Focusing on health-care providers' experiences in the COVID-19 crisis. The Lancet Global Health. 2020 Jun 1;8(6):e740-1.

12. Das, M., 2020. Social construction of stigma and its implications-observations from COVID-19.

13. Suárez-García I, de Aramayona López MM, Vicente AS, Abascal PL. SARS-CoV-2 infection among healthcare workers in a hospital in Madrid, Spain. Journal of Hospital Infection. 2020 Oct 1;106(2):357-63. 